\title{
Does obesity influence target organ damage and outcomes in patients with malignant phase hypertension? The West Birmingham Malignant Hypertension Project
}

\begin{abstract}
Alena Shantsila, Deirdre A Lane, D Gareth Beevers and Gregory YH Lip
Several studies have suggested that hypertension has a stronger detrimental impact on cardiovascular outcome in lean than in obese persons, but neutral or opposite results have also been reported. We investigated the impact of baseline body mass index (BMI) at presentation with the most severe form of hypertension, that is, malignant phase hypertension (MPH) on the primary outcome of 'death or dialysis' in these patients. A total of 184 patients (overall mean (s.d.) age 48 (13) years; $61 \%$ male; $62 \%$ White-European; 20\% African-Caribbean, 18\% South-Asian) from the West Birmingham MPH Register were included. The patients were grouped according to their BMI (underweight, normal weight, overweight and obese groups). Ninety-three primary outcomes occurred during a median (interquartile range) follow-up of 10.7 (5.8-18.6) years. No significant baseline differences in age or ethnicity were seen between the study groups. Overweight and obese patients included a larger proportion of females, but less smokers than those underweight or of normal weight. There was no inter-group difference in retinopathy $(P=0.25)$, proteinuria $(P=0.08)$, haematuria $(P=0.56)$ and left ventricular hypertrophy $(P=0.14)$. In univariate analyses, BMI was predictive of death or dialysis $(0.95(0.90-1.00), P=0.046)$ but multivariate analyses showed that only baseline age (odds ratio (95\% confidence intervals) 1.06 (1.03-1.09), $P<0.001)$, smoking $(2.89(1.40-5.92), P=0.004)$, creatinine level (1.01 (1.01-1.02), $P=0.001)$ and estimated glomerular filtration rates $(0.99(0.93-1.00), P=0.047)$ were independently associated with death or dialysis. BMI was not an independent predictor of adverse outcomes in MPH patients. Age, smoking status, creatinine levels and estimated glomerular filtration rates at diagnosis of MPH were independent predictors for death or dialysis in this high-risk population of hypertensive patients.
\end{abstract}

Hypertension Research (2013) 36, 546-549; doi:10.1038/hr.2012.222; published online 14 February 2013

Keywords: body mass index; malignant hypertension; obesity; outcomes

\section{INTRODUCTION}

Malignant phase hypertension (MPH) is the most severe form of hypertension usually defined clinically by the presence of very high blood pressure (BP) (office diastolic BP above $130 \mathrm{~mm} \mathrm{Hg}$ at the time of the diagnosis) accompanied by grade III or IV hypertensive retinopathy according to the classification of Keith et al. ${ }^{1,2}$ Previous studies have shown that if patients with MPH are left untreated $80 \%$ of them will die within 2 years of diagnosis. ${ }^{1}$ Although the introduction of modern multidrug antihypertensive therapy has resulted in considerable improvement of prognosis, MPH still represents a high-risk clinical entity with limited data available on long-term outcome. ${ }^{3}$

Several studies have suggested that hypertension has a stronger detrimental impact on cardiovascular outcome in lean than in obese persons, ${ }^{4}$ but neutral ${ }^{5}$ or opposite ${ }^{6}$ results have also been reported.
These findings suggest the potential importance of body mass index (BMI) as an outcome predictor in MPH. However, the current data on the prognostic significance of BMI in patients presenting with $\mathrm{MPH}$ are limited.

The aim of this study was to investigate the impact of BMI at presentation with MPH on target organ damage and death or dialysis in the large cohort of patients from the West Birmingham MPH study undergoing follow-up.

\section{METHODS}

A total of 184 subjects with MPH, their BMI measured at presentation and known vital status on 31 December 2006 (follow-up end time) were included in the analyses. MPH was defined clinically based on the presence of severe hypertension (office diastolic BP $>130 \mathrm{~mm} \mathrm{Hg}$ at the time of the diagnosis) together with bilateral retinopathy with haemorrhages, and/or cotton wool 
spots or exudates, with or without papilloedema, detected on fundoscopy (Figure 1). ${ }^{2,7}$ Patients with unilateral retinal features or papilloedema only were excluded from these analyses. Patients were assigned into four groups according their BMI at the time of diagnosis: underweight $\left(<21 \mathrm{~kg} \mathrm{~m}^{-2}\right)$, normal weight $\left(21.1-25.0 \mathrm{~kg} \mathrm{~m}^{-2}\right)$, overweight $\left(25.1-29.9 \mathrm{~kg} \mathrm{~m}^{-2}\right)$ and obese $\left(\geqslant 30.0 \mathrm{~kg} \mathrm{~m}^{-2}\right)$. For these analyses, target organ damage was defined as the

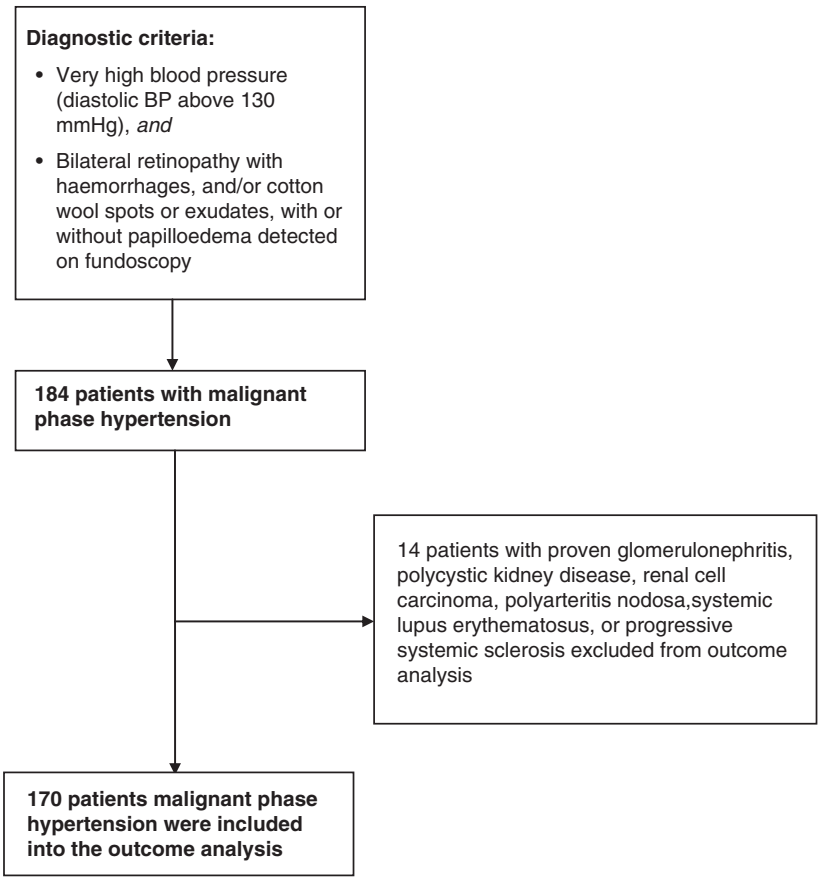

Figure 1 Flowchart of the patient selection for the study analyses. presence of one or more of the following at baseline: retinopathy, proteinuria, haematuria and left ventricular hypertrophy. Proteinuria was defined as absent (nil or trace $<30 \mathrm{mg} \mathrm{dl}^{-1}$ ), mild $\left(30-99 \mathrm{mg} \mathrm{dl}^{-1}\right.$ ) or moderate-to-severe $\left(\geqslant 100 \mathrm{mg} \mathrm{dl}^{-1}\right)$, with left ventricular hypertrophy identified based on Sokolow-Lyon electrocardiogram voltage criteria.

Patients with proven glomerulonephritis, polycystic kidney disease, renal cell carcinoma, polyarteritis nodosa, systemic lupus erythematosus or progressive systemic sclerosis $(n=14)$ at diagnosis were excluded, as target organ damage and death may be attributable to these underlying conditions rather than $\mathrm{BP}$ control. The total number of person-years of observation was calculated from date when patients were diagnosed with MPH until 31 December 2006 or development of an outcome event.

Statistical analyses were conducted using SPSS software, version 18.0 for Windows (Chicago, IL, USA). Categorical variables were compared using $\chi^{2}$-tests. Continuous normally distributed variables were compared using oneway analysis of variance with Tukey's post hoc tests, with the results expressed as mean (s.d.). Non-normally distributed values were compared using the Kruskal-Wallis test. Univariate and multivariate Cox regression analysis was used to assess the predictive value of BMI for the primary outcome. KaplanMeier estimates for the distribution of time from diagnosis to the primary end point were computed and log-rank analysis was performed to compare eventfree survival according to quartiles of BMI. All significant univariate predictors were entered into the model in order to determine independent predictors of death or dialysis. The need for dialysis was established by a renal specialist (or by multidisciplinary team meeting, if necessary) according to current guidelines accepted in the United Kingdom. The date of the first event occurred (that is, death or dialysis) was used for the analysis.

\section{RESULTS}

The baseline demographics according to the groups of BMI are listed in Table 1. The mean (s.d.) age at presentation was 48 (13) years, $61 \%$ were male, and $62 \%$ were White-European, $20 \%$ were AfricanCaribbean and $18 \%$ were South-Asian. There were no significant differences in age, ethnicity, systolic or diastolic BP between the study groups at baseline. However, there was a significant difference in

Table 1 Baseline demography for malignant hypertension patients by baseline BMI

\begin{tabular}{|c|c|c|c|c|c|}
\hline & $\begin{array}{l}\text { Underweight } B M I<21 \\
\qquad(\mathrm{n}=16)\end{array}$ & $\begin{array}{c}\text { Normal BMI 21.1-25.0 } \\
\qquad(\mathrm{n}=50)\end{array}$ & $\begin{array}{l}\text { Overweight BMI 25.1-29.9 } \\
\qquad(\mathrm{n}=66)\end{array}$ & $\begin{array}{c}\text { Obese } B M I \geqslant 30.0 \\
(n=52)\end{array}$ & P-value \\
\hline Age, years & $43(13)$ & $51(15)$ & $49(11)$ & $45(13)$ & 0.20 \\
\hline Male, $n(\%)$ & $10(63)$ & $37(74)$ & $43(65)$ & $23(44)$ & 0.017 \\
\hline Ethnicity, $n(\%)$ & & & & & 0.14 \\
\hline White-European & $10(62)$ & $34(68)$ & $41(62)$ & $29(56)$ & \\
\hline African-Caribbean & $0(0)$ & $11(22)$ & $14(21)$ & $12(23)$ & \\
\hline South-Asian & $6(38)$ & $5(10)$ & $11(17)$ & $11(21)$ & \\
\hline Systolic BP, mm Hg & $226(44)$ & $230(30)$ & $233(30)$ & $231(34)$ & 0.91 \\
\hline Diastolic BP, mm Hg & $147(15)$ & $144(20)$ & $141(19)$ & $146(19)$ & 0.42 \\
\hline Smoking, $n(\%)$ & $44(54)$ & $64(50)$ & $67(64)$ & $50(45)$ & 0.01 \\
\hline Creatinine, $\mathrm{mmoll}^{-1}$ & $150(121-213)$ & 133 (109-198) & $127(97-173)$ & $118(88-168)$ & 0.044 \\
\hline eGFR, $\mathrm{ml} \mathrm{min}^{-1}$ per $1.73 \mathrm{~m}^{2}$ & $47(35-72)$ & $53(38-66)$ & $61(38-73)$ & $48(29-56)$ & 0.062 \\
\hline \multicolumn{6}{|l|}{ Retinopathy, $n(\%)$} \\
\hline $\mathrm{HE}$ & $7(44)$ & $17(34)$ & $33(50)$ & $18(35)$ & 0.25 \\
\hline PHE & $9(56)$ & $33(66)$ & $33(50)$ & $34(65)$ & \\
\hline \multicolumn{6}{|l|}{ Proteinuria, $n(\%)$} \\
\hline Mild & $0(0)$ & $8(16)$ & $18(28)$ & $12(26)$ & 0.08 \\
\hline Moderate/severe & $10(62)$ & $20(41)$ & $23(36)$ & $24(51)$ & \\
\hline Haematuria, $n(\%)$ & $5(31)$ & $12(24)$ & $11(17)$ & $12(26)$ & 0.56 \\
\hline $\mathrm{LVH}, n(\%)$ & $11(73)$ & $34(71)$ & $40(63)$ & $24(50)$ & 0.14 \\
\hline \multicolumn{6}{|l|}{ Outcome } \\
\hline Death or dialysis, $n(\%)$ & $9(56)$ & $31(62)$ & $33(50)$ & $20(38)$ & 0.12 \\
\hline
\end{tabular}

Abbreviations: BMI, body mass index; BP, blood pressure; eGFR, estimated glomerular filtration rate MDRD (modification of diet in renal disease) formula, HE, haemorrhage and/or exudates; PHE, papilloedema and haemorrhage and/or exudates; LVH, left ventricular hypertrophy (Sokolow-Lyon criteria). 
Table 2 Predictors of outcomes (death or dialysis) in malignant hypertension

\begin{tabular}{|c|c|c|}
\hline Baseline characteristic & $\begin{array}{c}\text { Odds ratio (95\% } \\
\text { confidence intervals) }\end{array}$ & $\mathrm{P}$-value \\
\hline \multicolumn{3}{|l|}{ Univariate analysis } \\
\hline Age, years & $1.04(1.02-1.07)$ & $<0.0001$ \\
\hline Sex & $0.82(0.45-1.49)$ & 0.522 \\
\hline Ethnicity & $0.93(0.64-1.35)$ & 0.696 \\
\hline Smoker & $2.43(1.33-4.42)$ & 0.004 \\
\hline Retinopathy (both eyes) & $1.09(0.60-1.95)$ & 0.785 \\
\hline Proteinuria & $1.26(0.90-1.76)$ & 0.182 \\
\hline Body mass index, $\mathrm{kg} \mathrm{m}^{-2}$ & $0.95(0.90-1.00)$ & 0.046 \\
\hline Creatinine, $\mathrm{mmol}^{-1}$ & $1.01(1.01-1.02)$ & $<0.0001$ \\
\hline $\begin{array}{l}\text { Estimated glomerular filtration rate, } \\
\mathrm{ml} \mathrm{min}^{-1} \text { per } 1.73 \mathrm{~m}^{2}\end{array}$ & $0.98(0.97-0.996)$ & 0.014 \\
\hline \multicolumn{3}{|l|}{ Multivariate analysis ${ }^{\mathrm{a}}$} \\
\hline Age, years & 1.06 (1.03-1.09) & $<0.001$ \\
\hline Smoking & $2.89(1.41-5.92)$ & 0.004 \\
\hline Creatinine, mmoll-1 & $1.01(1.01-1.02)$ & 0.001 \\
\hline \multicolumn{3}{|l|}{ Multivariate analysis ${ }^{\mathrm{b}}$} \\
\hline Age, years & $1.05(1.02-1.08)$ & 0.001 \\
\hline Smoking & $3.02(1.47-6.21)$ & 0.003 \\
\hline $\begin{array}{l}\text { Estimated glomerular filtration rate, } \\
\mathrm{ml} \mathrm{min}^{-1} \text { per } 1.73 \mathrm{~m}^{2}\end{array}$ & $0.99(0.93-1.00)$ & 0.047 \\
\hline
\end{tabular}

aEnter method using all significant predictors from the univariate analysis except estimated glomerular filtration rate (because of the strong correlation with creatinine).

bEnter method using all significant predictors from the univariate analysis except creatinine (because of the strong correlation with estimated glomerular filtration rate).

gender distribution among the BMI groups, with a higher proportion of females in the obese group and smoking rates were highest in the 'overweight' group.

There were no signs of more severe target organ damage at presentation as evidenced by retinopathy $(P=0.25)$, proteinuria $(P=0.08)$, haematuria $(P=0.56)$ and left ventricular hypertrophy $(P=0.14)$ with increasing of BMI at presentation (see Table 1$)$. Mean creatinine level significantly increased with decreasing BMI $(P=0.044)$. There was a nonsignificant trend towards lower estimated glomerular filtration rates in patients from extreme weight groups (that is, underweight and obese, $P=0.062$ ).

Ninety-three primary outcomes of death from any cause or dialysis occurred during a median (interquartile range follow-up of 10.7 (5.818.6) years. There were no significant differences in all-cause mortality or dialysis between baseline BMI groups $(P=0.12$; Table 1$)$. On univariate regression analyses, significant predictors of death or dialysis were age, smoking, signs of nephropathy (higher creatinine level, lower estimated glomerular filtration rates) at presentation, and an increasing BMI (BMI entered as a continuous variable; Table 2). On multivariate analyses, independent predictors of death or dialysis were age (odds ratio (95\% confidence intervals) 1.06 (1.03-1.09), $P<0.001)$, smoking (2.89 (1.40-5.92), $P=0.004)$, creatinine level (1.01 (1.01-1.02), $P=0.001)$ and estimated glomerular filtration rates (0.99 (0.93-1.00), $P=0.047)$ but not BMI. Kaplan-Meier curves of event free survival in which patients were grouped by quartiles of BMI demonstrated that there were no differences in outcome between the groups (Log-rank test, $P=0.60$; Figure 2).

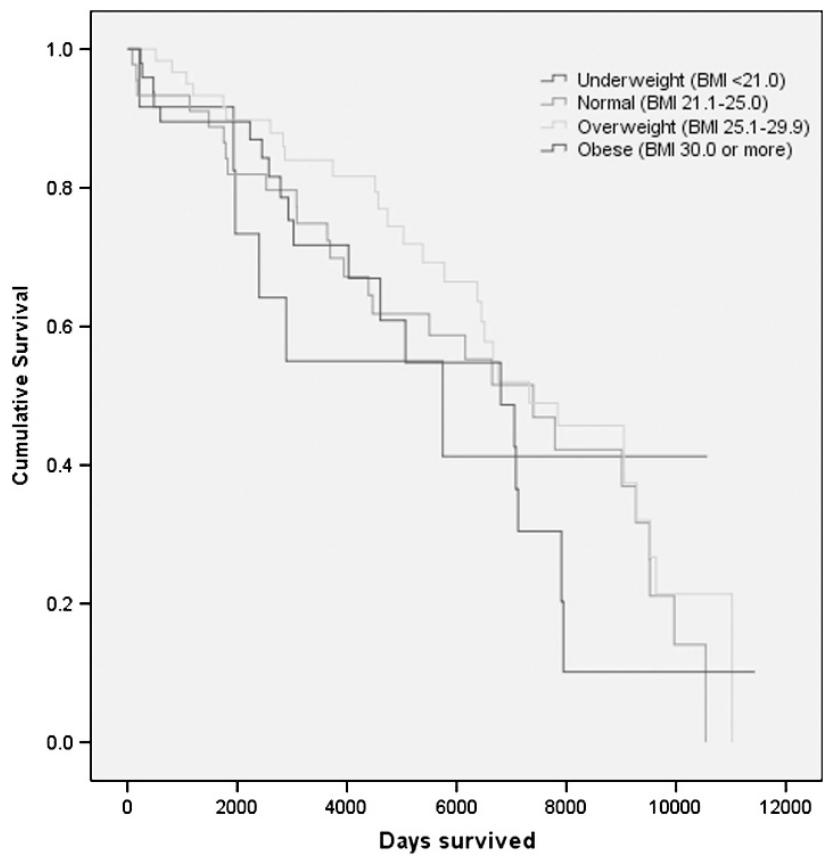

Figure 2 Kaplan-Meier curves of cumulative event-free survival (the primary outcome) according body mass index (BMI) quartiles (log-rank test, $P=0.60$ ). A full color version of this figure is available at the Hypertension Research journal online.

\section{DISCUSSION}

This study demonstrates that BMI at presentation did not predict allcause mortality or dialysis in patients with $\mathrm{MPH}$ and was not associated with higher rates of the target organ damage at baseline. Age, smoking status, creatinine levels and estimated glomerular filtration rates at diagnosis of MPH were independent predictors for death or dialysis in this high-risk population of hypertensive patients.

Despite the considerable development in the management of MPH, progressive deterioration of renal function remains a driving cause of morbidity and mortality. ${ }^{8,9}$ Obesity is an important risk factor for cardiovascular disease and therefore it came as a surprise that increased BMI was not predictive of death or dialysis on multivariate analyses in this study. Accumulating data indicate that MPH may have a distinct underlying pathophysiology, possibly associated with acute kidney injury/renal vasculitis. ${ }^{10}$ In such a setting, any weight loss may be secondary to the severity of the pathological process and subsequently the predictive value of BMI is lost after adjustment for a parameter of renal function.

\section{Limitations}

The study has some limitations, particularly that it is a retrospective analysis. However, the data set is based on prospectively collected data between 1977 and 2006, which is the largest available cohort of MPH patients. Also, there may have been changes in BMI over time, which we could not account for.

In conclusion, BMI at presentation with MPH does not predict prognosis after adjustment for other significant predictors of outcome. Age and renal function are the key drivers of adverse outcomes, which accords with previous research. 
1 Keith NM, Wagener HP, Barker NW. Some different types of essential hypertension: their course and prognosis. Am J Med Sci 1974; 268: 336-345.

2 Calhoun DA, Jones D, Textor S, Goff DC, Murphy TP, Toto RD, White A, Cushman WC, White W, Sica D, Ferdinand K, Giles TD, Falkner B, Carey RM. Resistant hypertension: diagnosis, evaluation, and treatment: a scientific statement from the American Heart Association Professional Education Committee of the Council for High Blood Pressure Research. Circulation 2008; 117: e510-e526.

3 Lip GY, Beevers M, Beevers DG. Complications and survival of 315 patients with malignant-phase hypertension. J Hypertens 1995; 13: 915-924.

4 Stamler R, Ford CE, Stamler J. Why do lean hypertensives have higher mortality rates than other hypertensives? Findings of the hypertension detection and follow-up program. Hypertension 1991; 17: 553-564.
5 Phillips A, Shaper AG. Relative weight and major ischaemic heart disease events in hypertensive men. Lancet 1989; 1: 1005-1008.

6 Kannel WB, Zhang T, Garrison RJ. Is obesity-related hypertension less of a cardio vascular risk? The Framingham Study. Am Heart J 1990; 120: 1195-1201.

7 Leishman AW. Hypertension: treated and untreated; a study of 400 cases. Br Med J 1959; 1: 1361-1368.

8 Lip GY, Beevers M, Beevers DG. Does renal function improve after diagnosis of malignant phase hypertension? J Hypertens 1997; 15: 1309-1315.

9 van den Born BJ, Koopmans RP, van Montfrans GA. The renin-angiotensin system in malignant hypertension revisited: plasma renin activity, microangiopathic hemolysis, and renal failure in malignant hypertension. Am J Hypertens 2007; 20: 900-906.

10 Shantsila A, Shantsila E, Lip GY. Malignant hypertension: a rare problem or is it underdiagnosed? Curr Vasc Pharmacol 2010; 8: 775-779. 